\title{
Inhalt
}

Vorwort

9

\section{Franz Schultheis}

Fotografie als Instrument, Methode und Erkenntnisform

soziologischer Forschung bei Pierre Bourdieu

Ein Gespräch zwischen Pierre Bourdieu und Franz Schultheis

Mit dem Objektiv sehen

Im Umkreis der Fotografie

Stephan Egger

Die Gestalt des Gesellschaftlichen

Zu Bourdieus »plastischer« Soziologie

61

Christine Frisinghelli

Anmerkungen zu den fotografischen Dokumentationen

von Pierre Bourdieu

Tassadit Yacine

Algerien - Matrix eines Werks

Akli Kebaili

Heimat und Fremdheit

Eine Zeugenschaft

Pierre Bourdieu

Für Abdelmalek Sayad 99

Franz Schultheis und Christine Frisinghelli

Orte und Geschichten

Das Fotoarchiv 107

Stephan Egger

Zum vermeintlichen Paradox einer Fotografie unter Herrschaftsbedingungen 
Autorinnen und Autoren, Mitwirkende 119

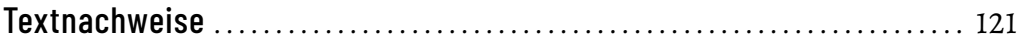

Bildnachweise 